Blieb er einmal im Texte stecken, so liess er sich durch seine Lehrerin wieder anshelfen und fubr dann fort. Verliess die Dame das Zimmer, so rief er ihr regelmässig nach: „Wo bist du denn mein Mätzchen? wo bist du, bist du? "Ausserdem rief er seine Herrin mit einem eigenthümlichen Lokton, den man sonst von einem Vogel der Art nicht vernimmt. Noch andere Worte wie die angeführten soll das Thierchen hervorbringen; da ich diese jedoch nicht gebört habe, auch bei ibnen die Einbildungskraft schon ein gut Theil thun kann, so will ich es mit ibnen lieber dahingestellt sein lassen. Keineswegs zweifle ich aber, dass das Sprachtalent des Vögelchens, welches sich bei den theilweise recht schwierigen Lauten so gut bewährt hat, bei einiger Sorgfalt und Ausdauer weiter auszubilden wäre.

Der Vogel ist 2 Jahre alt, sehr zahm und singt nicht, ausgenommen einen Triller, den er sich in letzter Zeit angeeignet hat und den er gewöhnlich an das "wo bist du, bist du?" anzuhängen pflegt. Die Stimme ist, wie schon angedentet, der eines Kindes von etwa 4 Jahren täuschend ähnlich. Das „st" in der Aussprache des Yogels hat viel Aehnlichkeit mit demselben Laute in der plattdeutschen Sprache, ist also eine Mischung aus "st" und "sch."

Die Frau Prof. Teschner ist gern bereit, jedem sieh dafür Interessirenden den Vogel zu zeigen, und kann ich den Männern und Freunden der Ornithologie nur empfehlen, sich baldigst diesen Genuss zu verschaffen.

Berlin, im Mai 1868.

Wilh. Lühder.

\title{
Fringilla chloris als Höhlenbriiter.
}

Bei einer Partie, die ich mit dem Stabsarzt Dr. Kutter von Fraustadt aus nach dem Röbrsdorfer-Wald am 28. April 1866 machte, ergriff ich Fringilla chloris $q$ anf dem Neste, welches in einem 5 Zoll bohen, 3 Zoll breiten und 5 Zoll tiefen Loche einer Kopfweide sass.

Alexander von Homeyer. 